\title{
Chronic Infantile Neurological Cutaneous and Articular (CINCA) syndrome: a review
}

\author{
Martina Finetti ${ }^{*}$ (D), Alessia Omenetti ${ }^{2}$, Silvia Federici ${ }^{1}$, Roberta Caorsi ${ }^{1}$ and Marco Gattorno ${ }^{1}$
}

\begin{abstract}
Introduction: The Chronic Infantile Neurological Cutaneous and Articular (CINCA, or Neonatal-onset multisystem inflammatory disease NOMID) is a rare autoinflammatory disease identified in 1987 by Prieur et al., typically characterized by the triad of skin rash, arthropathy and central nervous system manifestations. It represents the most severe phenotype of the cryopyrin-associated periodic syndrome (CAPS).

Clinical description and etiology: The syndrome is due to autosomal dominant gain of function mutations in $N L R P 3$, which encodes a key component of the innate immunity that regulates the activation and secretion of interleukin (IL)-1ß. From the first days of life, patients display an urticarial rash in association with chronic inflammation with a typical facies featured by frontal bossing and saddle back nose. The CNS manifestations include chronic aseptic meningitis leading to brain atrophy, mental delay and sensorineural hearing loss. Chronic polyarthritis and alteration of the growth cartilage also may be present. CINCA/NOMID diagnosis is made clinically, based on the presence of characteristic features. The detection of NLRP3 mutations is diagnostic in $65-70 \%$ of cases. Indeed, up to $40 \%$ of affected patients are negative for germline NLRP3 mutations and several subjects are carriers of somatic mosaicism. Due to the pivotal role of Cryopyrin in the control of Caspase-1 activation and the massive secretion of active IL-1 $\beta$ observed in cryopyrin-mutated individuals, anti-IL1 treatment represents the standard therapy.

Conclusion: Prognosis of CINCA/NOMID syndrome has been changed by the availability of anti-IL1 drugs. Nowadays, the use of anti-IL-1 drugs has sensibly reduced the risk of developing main complications such as severe intellectual disability, hearing-loss and amyloidosis, if treatment is started early on.
\end{abstract}

Keywords: Autoinflammation, Cryopyrinopathies, Urticarial rash, Aseptic meningitis, Hearing loss, IL-1

\section{Background}

Cryopyrin-associated periodic syndromes (CAPS) are inherited autoinflammatory conditions characterized by chronic systemic inflammation due to an abnormal regulation of the innate immune system. Three diseases of rising severity belong to this group: Familial Cold Autoinflammatory Syndrome (FCAS), Muckle-Wells syndrome (MWS) and Chronic Infantile Neurological Cutaneous and Articular (CINCA, or Neonatal-Onset Multisystem Inflammatory Disease, NOMID), with the latter being the most severe form of CAPS spectrum. Disease onset usually occurs within the first hours/days of life and it is characterized by intermittent fever (that may be of low grade or even absent), urticarial rash and

* Correspondence: martina81@tiscali.it

1UO Pediaria II, G. Gaslini Institute, Genoa, Italy

Full list of author information is available at the end of the article persistent elevation of acute phase reactants. A neurological involvement featured by chronic aseptic meningitis and papilledema is usually present at disease presentation and may lead to brain atrophy, severe intellectual disability and hearing loss. Hypertrophic arthropathy with contractures and bone deformity (frontal bossing, patellar overgrowth) is also typical of this form.

\section{Disease name/synonyms}

Chronic infantile neurological cutaneous and articular (CINCA) syndrome is also called Neonatal onset multisystemic inflammatory disease (NOMID), Infantile-onset multisystem inflammatory disease (IOMID) and PrieurGriscelli syndrome (OMIM 607115). 


\section{Definition and classification}

CINCA/NOMID syndrome is the prototype of an inherited autoinflammatory disorder due to mutation of a gene encoding the NLPR3 (or cryopyrin) protein, which is involved in the activation of the inflammatory response. It belongs to the group of the so-called inflammasomepathies, together with other conditions associated to mutations of genes that are members of the same protein family (NLRP12, NLRC4, NLRP12).

\section{Epidemiology}

It is estimated that globally the whole spectrum of CAPS has a prevalence of 1-2 cases in every 1 million [1] and 360,000 [2] people in the US and France, respectively. According to a prospective surveillance of children with CAPS performed in Germany during a time period of 3 years by Lainka et al., the incidence of CAPS in Germany corresponds to 2-7 newly diagnosed patients $\leq 16$ years per year [3].

\section{Clinical description}

CINCA/NOMID syndrome represents the most severe phenotype in the context of the clinical spectrum of CAPS (Table 1).

In a recent study by Levy et al. [4] the whole spectrum of CAPS in adult and pediatric patients has been described in a large series of 136 patients enrolled in the Eurofever International Registry. The median onset age was 0.8 years (range $0.1-5$ ) while the median age at diagnosis was 15 years (range 5-36) with a mean delay of diagnosis of 14 years. Seventy-eight patients (57\%) had a chronic course with symptoms almost daily, whereas fifty-eight (43\%) experienced only acute episodes. Fever, skin rash and musculoskeletal involvement were the most prevalent features (observed in 84, 97 and $86 \%$ of patients, respectively) and were observed in all the 3 diseases (FCAS, MWS and CINCA/NOMID).

In general, CINCA/NOMID children present during the first days of life with a chronic urticarial rash associated to persistent low-grade fever and sustained elevation of acute phase reactants. The rash is non-pruritic and it changes distribution during the day, without vasculitic alterations (Fig. 1).

Patients display a typical "facies", featured by frontal bossing, large cephalic perimeter and saddle-back nose (Fig. 2).

If untreated, these patients develop permanent CNS damages as consequence of chronic inflammation [5]. Chronic aseptic meningitis may cause intracranial pressure to increase, resulting in hydrocephalus, brain atrophy and chronic papilledema (Fig. 3). Neurological symptoms typical of CINCA/NOMID are characterized by chronic irritability, intellectual disability, headache, early morning nausea, vomiting and, rarely, seizures. In the Eurovefer registry the most frequent severe neurological manifestation was chronic meningitis, that was observed in $26 \%$ of patient. Other major neurological features (seizures, hydrocephalus, mental delay) were reported in $12 \%$ of the whole CAPS population.

The most frequent inflammatory eye manifestation is conjunctivitis. Persistent papilledema is rather common and it may cause optic nerve atrophy with progressive vision loss if left untreated [6, 7]. Anterior uveitis can contribute to the progressive vision loss. In the study of Dollfus et al. [8] the ocular manifestations in CINCA/ NOMID patients $(n=31)$ were described with a mean follow up of 11.5 years (2 to 32 years). The first ocular sign occurred at the mean age of 4.5 years (1-9 years), and it was represented by red eyes $(n=9)$, decreased vision $(n=7)$, strabismus $(n=4)$, nystagmus $(n=2)$ and photophobia $(n=2)$. During follow-up, 8 patients complained visual loss, all of them had signs of optic nerve lesion (i.e. optic disc edema in 2 patients and optic atrophy in 6 subjects), while 6 had also corneal involvement. In most patients, anterior ocular inflammation was featured by a mild to moderate anterior uveitis ( 9 out of 16 patients), while posterior inflammation seemed to occur less frequently. Optic disc abnormalities occurred in 26 patients (84\%) and included optic disc edema and, less frequently, pseudopapilledema and optic atrophy. Anterior segment manifestations were observed in 13 patients (42\%). Disease-related visual acuity loss in at least 1 eye

Table 1 Cryopyrin associated periodic syndrome (CAPS): main clinical features

\begin{tabular}{|c|c|c|}
\hline $\begin{array}{l}\text { Familial cold autoinflammatory } \\
\text { syndrome (FCAS) }\end{array}$ & Muckle-Wells syndrome (MWS) & NOMID/CINCA \\
\hline - Autosomal dominant & - Autosomal dominant & $\begin{array}{l}\text { - Autosomal dominant } \\
\text { - Sporadic }\end{array}$ \\
\hline $\begin{array}{l}\text { - Cold-induced: } \\
\text { - Fever } \\
\text { - Rash } \\
\text { - Conjunctivitis } \\
\text { - Arthralgia }\end{array}$ & $\begin{array}{l}\text { - Fever } \\
\text { - Urticarial rash } \\
\text { - Conjunctivitis } \\
\text { - Arthralgia } \\
\text { - Sensorineural deafness } \\
\text { - AA amyloidosis (in } 25 \% \text { of patients) } \\
\text { leading to renal failure }\end{array}$ & $\begin{array}{l}\text { - Fever } \\
\text { - Urticarial rash } \\
\text { - Conjunctivitis } \\
\text { - Visual and intellectual damage } \\
\text { - Sensorineural deafness } \\
\text { - Progressive chronic meningitis } \\
\text { - Destructive arthritis } \\
\text { - AA amyloidosis leading to renal failure }\end{array}$ \\
\hline
\end{tabular}




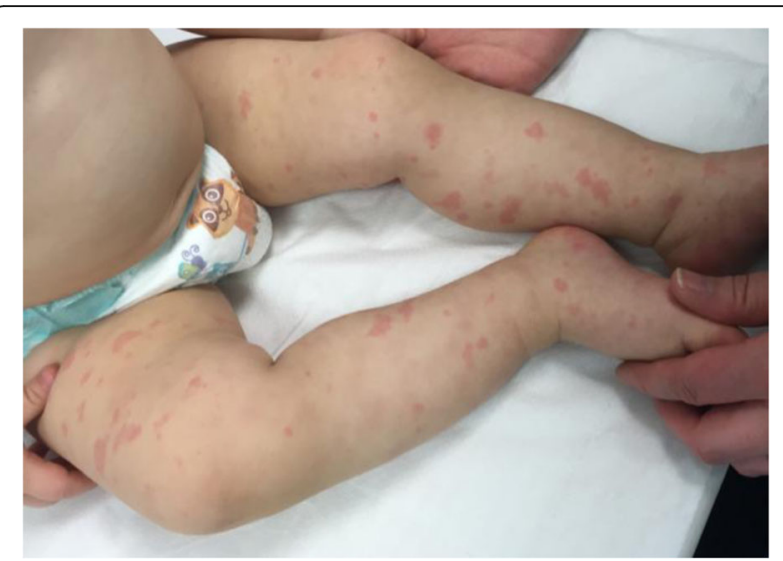

Fig. 1 Urticarial rash of CAPS patient

was reported in 8 patients (26\%). Posterior synechia, glaucoma, and white iritis were not observed in any patient.

Persistent cochlear inflammation may lead to sensorineural hearing loss usually occurs within the first years of life in a relevant percentage of untreated patients (42\% of CAPS patients enrolled in Eurofever Registry, Levy et al.). In a prospective study performed in 2013 by Neda Ahmadi et al. [9], data regarding clinical aspects, audiologic phenotype and fluid attenuation inversion recovery MRI (FLAIR-MRI) were collected in CAPS

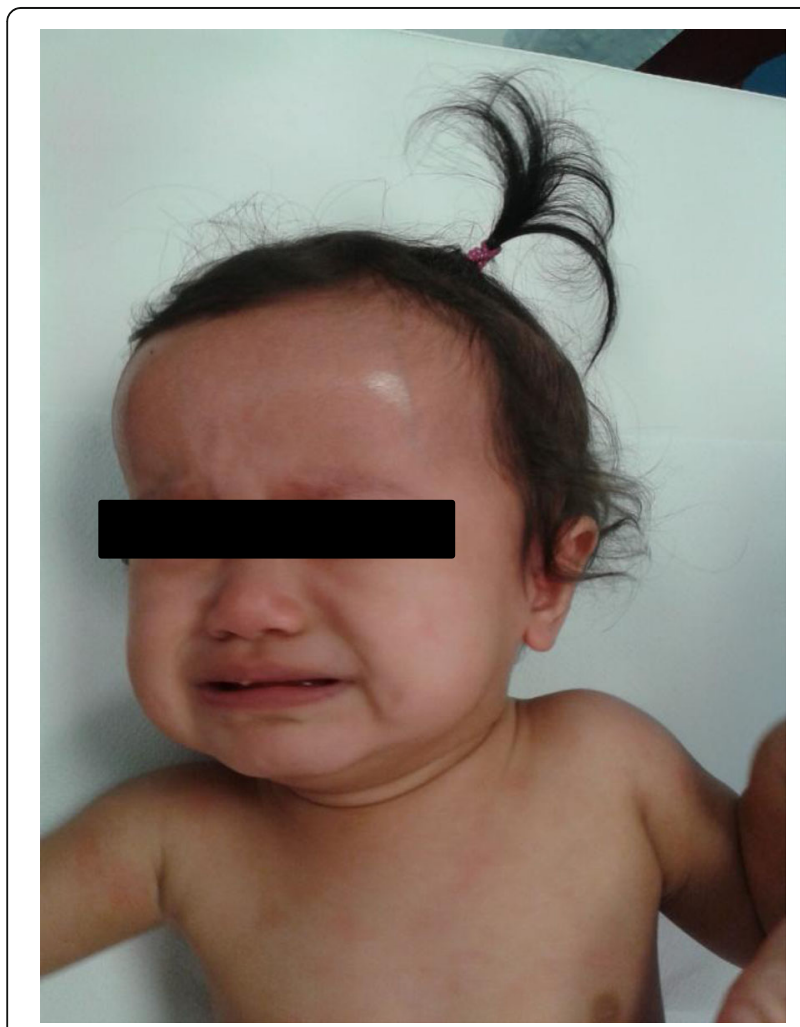

Fig. 2 Typical CINCA/NOMID "facies" featured by frontal bossing, large cephalic perimeter and saddle-back nose patients $(n=57)$ including 31 CINCA/NOMID subjects. Complete audiological data were obtained in $70 \%$ of ears and displayed conductive, mixed and sensorineural hearing loss in 11, 13 and 61\% of CINCA/NOMID ears, respectively. The latter was worse in the higher frequencies. Cochlear enhancement on FLAIR-MRI sequences was observed mainly in CINCA/NOMID $(n=26)$ and it appeared to be an accurate predictor of cochlear hearing loss.

Approximately $60 \%$ of CINCA/NOMID patients have prominent arthropathy, most frequently involving large joints as knees [10]. It usually begins during childhood and causes deformities that persist in adult age, resulting in early degenerative arthropathy and joint contractures. Histological analysis of growth cartilage displays a complete disorganization and irregular metachromasia of cartilage substance, but no inflammatory cell infiltrates [11]. In a 2007 study by Hill et al., radiographs were performed in a total of 20 CINCA/NOMID patients and bone abnormalities were detected in 11 out of 20 knees of patients. These findings included enlargement and deformities of femora and patellae in all the patients, without evidence of synovitis. The mechanism leading to articular damage is likely represented by an abnormal endochondral bone formation. Patellar premature ossification and overgrowth are typical, although rare, findings in CINCA/NOMID [7]. A chronic polyarthritis may also be present, sometimes leading to bone erosions. The multisystemic involvement characteristic of CINCA/NOMID syndrome has a severe impact on the quality of patient life [12].

\section{Aetiology-genetics}

As aforementioned, CINCA/NOMID represents the most severe phenotype of CAPS, monogenic diseases due to autosomal dominant inheritance of mutations in the NLRP3 gene (formerly known as cold-induced autoinflammatory syndrome 1, CIAS1), which encodes the NLRP3 protein also termed cryopyrin. NLRP3 variants causing CAPS are missense mutations resulting in a gain of function that, thus, enhance NLRP3 activity. To date, approximately $170 N L R P 3$ variants have been described and associated to either CINCA/NOMID or to milder phenotypes of the NLRP3-driven clinical spectrum including FCAS and MWS (http://fmf.igh.cnrs.fr/ISSAID/ infevers/) [9]. Almost all the NLRP3 mutations so far identified have been observed within the exon 3 , which is responsible for encoding the NACHT domain, crucial for cryopyrin oligomerization. However, although patients with FCAS and MWS tend to show familial inheritance patterns, CINCA/NOMID syndrome usually occurs de novo, and approximately $50-65 \%$ the patients with a CINCA/NOMID phenotype lack detectable mutations in the NLRP3 coding region [13-16]. It has been suggested that different genes or a modifier gene could 


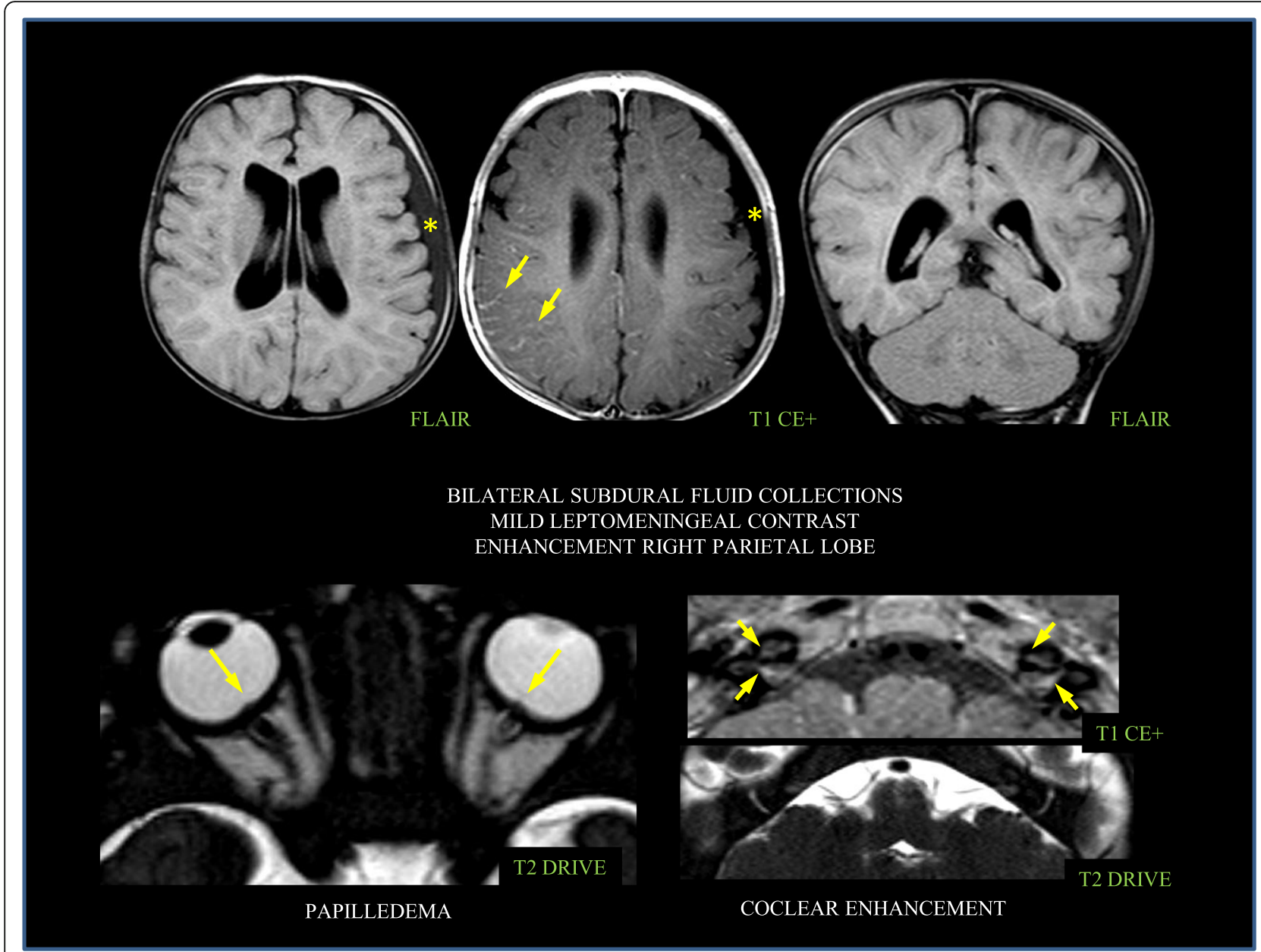

Fig. 3 MR features of CINCA/NOMID brain (subdural fluid collections, leptomeningeal contrast, papilledema, coclear enhancement)

be involved in these latter cases, although they do not differ clinically from those carrying NLRP3 mutations. In the past few years somatic NLRP3 mosaicism rather than heterozygous germ-line mutation has been detected in up to $69.2 \%$ [17] of patients presenting symptoms typical of CINCA/NOMID [17-22]. Thus, for a majority of genetically negative CINCA/NOMID patients, the disease onset may be caused by low-level mosaicism in the absence of detectable NLRP3 gene mutations by ordinary genomic sequencing [18-20]. NLRP3 mosaicism is thus an established major cause of CINCA/NOMID [17]. However, only recently, insights regarding the relevance of this mechanism were provided in other CAPS phenotypes [23, 24]. Namely, a variable degree $(5.5-34.9 \%)$ of somatic NLRP3 mosaicism vertical transmission was detected in patients with a MWS phenotype, pointing at somatic NLRP3 mosaicism as shared genetic mechanism in the whole CAPS spectrum, not restricted to CINCA/NOMID clinical picture $[23,24]$.

\section{Aetiology- pathophysiology}

The main functional effect of genetic background causing CAPS is the abnormal activation of innate immunity cells by endogenous and exogenous stimuli. CAPS may be considered the prototype of monogenic autoinflammatory diseases that, compared to autoimmune conditions, are featured by an apparent secondary role of the adaptive branch of the immune response, as suggested by the lack of self-reactive $\mathrm{T}$ cells and/or circulating autoantibodies and by the absence of a clear class II MHC association [25]. NLRP3 actually belongs to Nucleotide-binding domain and Leucine-rich repeat containing Receptor (NLRs) family (also known as Nucleotide-binding Oligomerization Domain (NOD)Like Receptors), which act as cytosolic patternrecognition receptors (PRRs) [26]. As a NLRs member, NLRP3 physiologically functions as danger sensor and undergoes activation following several insults, including both exogenous Pathogen-Associated Molecular Patterns (PAMPs) and the endogenous Damage-Associated 
Molecular Patterns (DAMPs) [27, 28]. Once triggered, NLRP3 interacts with other intracellular proteins and assemblies into a multiprotein complex called Inflammasome, a key player in IL-1 $\beta$ pathway activation. Unlike most cytokines, indeed, the pro-inflammatory IL-1 $\beta$ lacks a secretory signal peptide and it is released by monocytes through a non canonical pathway including two steps [29-31]. (Fig. 4) First, the 33-kD IL-1 $\beta$ precursor pro-IL-1 $\beta$ is induced by bacterial products (e.g. lipopolysaccharide, LPS) and accumulates in the cytosol. Secondarily, when a second hit triggers NLRP3, the inactive pro-IL-1 $\beta$ is converted into its mature $17-\mathrm{kD}$ form [32]. Following activation, NLRP3 oligomerizes and binds the adaptor Apoptosis-associated Speck-like protein containing a CARD (ASC) via its Pyrin (PYD) domains. NLRP3-ASC complex then directly activates pro-caspase1 into the active proteolytic enzyme caspase1, which, in turn, cleaves the IL- $1 \beta$ and IL-18 precursors into their bioactive forms [32]. This tight and complex control of IL- $1 \beta$ processing and secretion is linked to the powerful properties of this proinflammatory cytokine and it is necessary in order to avoid adverse effects related to its excessive release [33, 34]. The unrestrained IL- $1 \beta$ secretion occurring in CAPS patients further proves this concept. CAPS, indeed, may be actually considered intrinsic cryopyrinopathies in which gain of function mutations primarily affecting NLRP3 cause cells to display a constitutively turned-on inflammasome [35]. This condition releases inflammasome from the need of a normally required second signal (i.e. ATP), leading to caspase-1-driven IL-1 $\beta$ over-production [36]. Several data derived from either in vitro, in vivo and $e x$ vivo studies unveiled that NLRP3 mutations and redox alterations work together in determining CAPS IL-1 $\beta$ pattern of secretion. Indeed, factors inducing cellular stress may give rise to persistent activation of innate immunity. In the presence of overly active danger sensor such as NLRP3, it is conceivable that IL-1-mediated signaling cascade may be enhanced. Reactive oxygen species (ROS)-associated genes represent, indeed, one of most differentially expressed set in severe CAPS [37]. For years, oxidative stress has been investigated as potential key player in the activation of NLRP3inflammasome [34, 38]. NLRP3-mutated CAPS monocytes basally display elevated levels of ROS and fragmented mitochondria, and these stress marks are dramatically worsened by TLR stimulation [39]. CAPS resting monocytes also exhibit higher levels of antioxidants, and redox response to PAMPs is also altered, with faster upregulation of the antioxidant machinery which rapidly undergoes exhaustion [40]. As result, CAPS patients are uniquely featured by a dramatically anticipated IL1 $\beta$ secretion [40]. As aforementioned, once elicited, IL-1 $\beta$ pathway disruption occurring in cryopyrinopathies triggers a cascade of complex cellular events leading to aberrant homeostatic tissue responses. In conclusion, the research field exploring CINCA/NOMID pathogenesis is continuously in progress. A recent newly

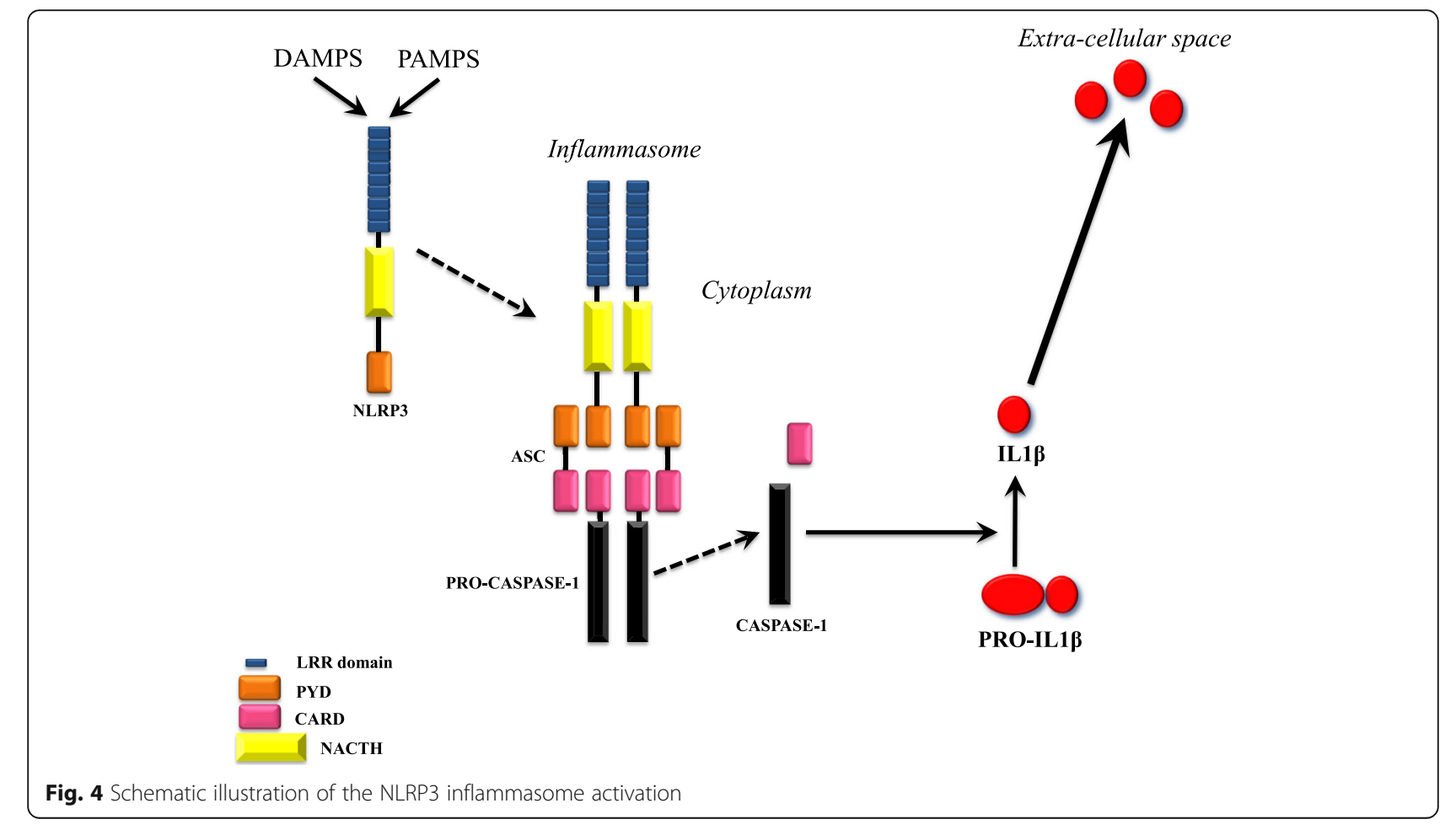


identified mechanism based on NLRP3 inflammasome acting also as an extracellular oligomeric complex thus causing persistent inflammatory response further expands the growing complexity underlying CINCA/NOMID pathogenesis and open the field to a wide spectrum of cross-talking signaling potentially involved [41].

\section{Diagnosis and diagnostic methods}

The characteristic clinical picture, starting with a persistent urticarial rash associated to systemic inflammation signs during the first days or week of life usually leads to the suspicion of a diagnosis CINCA/NOMID syndrome [42]. The persistence of the symptoms despite the antibiotic and/or antiviral treatment and the partial control of the symptoms achieved by steroids have to address the suspicion through a cryopyrin associated periodic syndrome. Even if laboratory alterations are not specific, CINCA/NOMID patients may display persistent elevation of acute phase reactants, leukocytosis and chronic anemia. Recently, evidence-based clinical criteria for CAPS and other inherited periodic fevers have been developed, on the basis of the multivariate analysis performed on a large number of patients enrolled in the Eurofever international registry [43]. Even if these criteria were developed in patients presenting a recurrent disease course, $100 \%$ of the CINCA/NOMID patients enrolled in the Eurofever registry were correctly identified. New specific criteria for CAPS, including the most severe CINCA/NOMID phenotype are currently under development (Kummerle et al., in preparation). In order to confirm the diagnosis the molecular analysis of NLRP3 gene is surely required. Due to the severe phenotype, usually de-novo mutations are detected. As already stated, up to $35-40 \%$ of patients with a clear CINCA/ NOMID phenotype turn out to be negative for germline mutations of NLRP3 [17]. Almost 70\% of these patients are, instead, carriers of a somatic mosaicism [44], that can involve even a very low percentage of the cells of myeloid lineage [17]. There is a general consensus among experts that the clinical picture of CINCA/ NOMID is sufficient to point out the diagnosis even in the absence of a positive genetic test [45].

\section{Differential diagnosis}

The disease onset of CINCA/NOMID syndrome usually occurs early on, often within the first months of life. Therefore, in the beginning, an infectious disease is often suspected. A diagnostic algorithm in children with fever and skin rash has been recently developed in order to differentiate CINCA/NOMID from the other cryopyrinopathies (FCAS and MWS) and autoinflammatory diseases (i.e. CANDLE syndrome and systemic onset juvenile idiopathic arthritis) characterized by a similar clinical picture [42]. Patients with a severe form of mevalonate kinase deficiency (MKD) may present a very early onset with a chronic and subchronic disease course. An urticarial skin rash can also be present, even if without the daily occurrence observed in CAPS. TNFreceptor associated periodic fever (TRAPS) usually present with long lasting fever episodes followed by clinical remission. An urticarial skin rash has been observed, at least occasionally, in $25 \%$ of TRAPS patients enrolled in the Eurofever registry [46]. However, the presence of other more typical manifestations (erythematous migratory rash, fasciitis, periobrital oedema, abdominal and chest pain) help in the differentiation with CAPS. Due to the lack of urticarial rash, other forms of periodic fever, such as familiar Mediterranean fever (FMF) and PFAPA (periodic fever with adenitis pharingitis and aphtosis) syndrome do not usually enter in the differential diagnosis with CAPS.

\section{Genetic counseling}

Patients affected by CINCA/NOMID syndrome and carrying germinal mutation in NLRP3 gene have the chance of $50 \%$ to transmit the disease to each child, since the modality of transmission is autosomal dominant. In case of somatic mosaicism this risk depends on the possible presence of somatic mutations in reproductive organs in the parents [23].

\section{Antenatal diagnosis}

In presence of an affected parent the search for the NLRP3 mutations can be performed through prenatal diagnosis techniques (chorionic villus sampling or amniocentesis). The availability of anti-IL-1 treatment has dramatically changed the long-term prognosis and the quality of life of CAPS patients with a mild and intermediate phenotypes that are usually transmitted with the typical autosomal pattern. Conversely, the presence of a severe neurological involvement in patients with CINCA/NOMID phenotype might be associated to the possibility to develop various degree of neurological complications and hearing loss, even with an adequate and timely treatment (see below). As stated above this latter condition is usually associated to the presence of de-novo mutations or somatic mosaicisms. This should be carefully considered in the process of genetic counseling, concerning possible prenatal and/or pre-implantation genetic diagnosis.

\section{Management including treatment}

The discovery of the mechanism of action of cryopyrin in the control of caspase- 1 activation and the aberrant secretion of IL- $1 \beta$ observed in patients with this disease suggested that IL-1 blockage might be an effective treatment (Table 2). 
Table 2 Results of the main studies analyzing the use of antilL1 drugs in CINCA syndrome

\begin{tabular}{|c|c|c|c|c|c|c|}
\hline Study & $\begin{array}{l}\text { Type of } \\
\text { study }\end{array}$ & Type of drug & $\begin{array}{l}\text { Number of } \\
\text { patients } \\
\text { enrolled }\end{array}$ & $\begin{array}{l}\text { Study } \\
\text { duration } \\
\text { (months) }\end{array}$ & $\begin{array}{l}\text { Number of patients who reached } \\
\text { primary endpoint }\end{array}$ & $\begin{array}{l}\text { Number of patient } \\
\text { with central nervous } \\
\text { system remission }\end{array}$ \\
\hline $\begin{array}{l}\text { Goldbach-Mansky } \\
\text { et al. } 2006 \text { [7] }\end{array}$ & $\begin{array}{l}\text { Open- } \\
\text { label }\end{array}$ & anakinra & 18 CINCA & 6 & $18 / 18$ & $\begin{array}{l}\text { In } 12 \text { patients intracranial } \\
\text { pressure, protein levels and } \\
\text { white cells count decreased } \\
\text { significantly }\end{array}$ \\
\hline $\begin{array}{l}\text { Lepore et al. } 2010 \\
\text { [12] }\end{array}$ & $\begin{array}{l}\text { Open- } \\
\text { label }\end{array}$ & anakinra & $\begin{array}{l}14 \text { CAPS: } \\
-10 \text { CINCA } \\
-4 \text { MWS }\end{array}$ & 36 & $14 / 14$ & Not evaluated \\
\hline $\begin{array}{l}\text { Sibley et al. } 2012 \\
\text { [5] }\end{array}$ & $\begin{array}{l}\text { Open- } \\
\text { label }\end{array}$ & anakinra & 26 CINCA & 60 & $26 / 26$ & $\begin{array}{l}\text { Significant decrease of CSF } \\
\text { leukocyte count at } 36 \text { and } \\
60 \text { months ( } p=0.0026 \text { and } 0.0076)\end{array}$ \\
\hline $\begin{array}{l}\text { Hoffman et al. } \\
2012 \text { [58] }\end{array}$ & $\begin{array}{l}\text { Open- } \\
\text { label }\end{array}$ & rilonacept & $\begin{array}{l}101 \text { CAPS (FCAS } \\
\text { or MWS) }\end{array}$ & 18 & $\begin{array}{l}\text { Mean key symptom score at week } \\
72 \text { reduced from } 2.6 \text { to } 0\end{array}$ & Not evaluated \\
\hline $\begin{array}{l}\text { Caorsi et al. } 2013 \\
\text { [53] }\end{array}$ & $\begin{array}{l}\text { Open- } \\
\text { label }\end{array}$ & canakinumab & $\begin{array}{l}13 \text { CAPS: } \\
-7 \text { CINCA } \\
-4 \text { MWS } \\
-2 \text { overlap } \\
\text { CINCA/MWS }\end{array}$ & 12 & $\begin{array}{l}\text { Complete response }^{\mathrm{b}} \text { : } \\
\text { Baseline: } 5 / 13 \\
\text { Last Follow-up: 8/13 }\end{array}$ & Not evaluated \\
\hline $\begin{array}{l}\text { Sibley et al. } 2015 \\
\text { [55] }\end{array}$ & $\begin{array}{l}\text { Open- } \\
\text { label }\end{array}$ & canakinumab & 6 CINCA & 24 & $\begin{array}{l}\text { Full remission }{ }^{c} \\
\text { at month } 6: 0 / 6 \\
\text { Inflammatory remission }{ }^{d} \text { at month } \\
6: 4 / 6\end{array}$ & 6 months: 0/6 \\
\hline
\end{tabular}

${ }^{a}$ CNS involvement: abnormal CSF leukocyte count; ${ }^{b}$ complete response: absent or minimal disease activity at the global assessment with acute phase reactants within the normal range; ${ }^{C}$ Full remission: remission of patient-reported clinical components and measures of systemic inflammation and CNS inflammation; ${ }^{d}$ Inflammatory remission: CRP $\leq 10 \mathrm{mg} / \mathrm{L}$ and global diary score remission

Initially, isolated case reports and small studies showed the dramatic effects of IL-1 receptor antagonist (anakinra) in the control of rash and other systemic manifestations in MWS [45], FCAS [47] and CINCA/ NOMID $[7,36,48]$ patients. The long-term efficacy and safety of anakinra in CINCA/NOMID were described two distinct studies conducted in Italy and France, respectively $[12,49]$. Namely, data derived from both analyses indicated that anakinra regimen was safe and effective on the long-term, and that it was associated with a dramatic amelioration of the quality of life [12]. Sibley et al. published an open-label, long-term followup study on a cohort of 26 CINCA/NOMID patients treated with anakinra $1-5 \mathrm{mg} / \mathrm{kg} /$ day for at least 36 months [5]. In particular, the study aimed at evaluating the efficacy and safety of anti-IL-1 therapy in controlling systemic and organ-specific inflammation and in preventing the progression of organ damage. Sustained improvements in diary scores, parent's/patient's and physician's global scores of disease activity, parent's/patient's pain scores, and inflammatory markers were observed during all the period of the study. Despite a general good control of clinical manifestations (including hearing loss, ocular manifestations and headache) and laboratory parameters, few patients displayed a persistent, although mild, inflammation of CNS, and treatment with anti-IL1 did not prevent the progression of the bone involvement. Overall, this study provided evidence of sustained efficacy of anti-IL-1 in CINCA/NOMID without occurrence of significant adverse effects for up to 5 years. Anakinra was approved for the CINCA/NOMID form of CAPS in children older than 8 months in the US in early 2013 and for all forms of CAPS (FCAS, Muckle-Wells and CINCA/NOMID) in the EU in November 2013. The same good results have been also achieved with other newer anti-IL-1 including rilonacept (a fully human dimeric fusion protein that incorporates the extra-cellular domain of both IL-1 receptor components) and canakinumab (a fully human anti-interleukin-1 $\beta$ monoclonal antibody that selectively blocks IL-1 $\beta$ ). Since the efficacy of rilonacept has been demonstrated only in patients with the milder phenotype [50], this drug is approved for FCAS or MWS patients older than 11 years in US. Canakinumab is used subcutaneously at a starting dose of $150 \mathrm{mg}$ (or $2 \mathrm{mg} / \mathrm{kg}$ ) every 8 weeks [51]. However, as described in the following paragraphs, patients with CINCA/NOMID syndrome often require a higher dose $(4 \mathrm{mg} / \mathrm{kg})$ and frequency of administration [52, 53] Canakinumab is now approved in Europe and US for the use in all subtypes of CAPS in patients older than 2 years. The percentage of complete response to these drugs is generally quite high. However, a partial response, mainly related to a persistent elevation of acute phase reactants despite a satisfactory control of the clinical manifestations has been reported either with the use of Anakinra and Canakinumab in the Eurofever registry [54]. In Kuemmerle-Deschner et al. 2011 study [52], an open-label, multicentre, phase III study evaluating the 
safety and efficacy of canakinumab in the largest cohort of CAPS subjects, 32 CINCA/NOMID patients received subcutaneous canakinumab (i.e. $150 \mathrm{mg}$ or $2 \mathrm{mg} / \mathrm{kg}$ $\leq 40 \mathrm{~kg}$ every 8 weeks) for up to 2 years, and changes from baseline in clinically significant abnormality of neurological, audiogram and ophthalmological assessments were evaluated. Regarding neurological involvement, 4 CINCA/NOMID patients had abnormal findings at baseline (i.e. bilateral hearing loss, polyneuropathy, bilateral carpal tunnel syndrome, language-based learning disability, chronic headache). The successive neurological assessments performed in the next 2 years during canakinumab therapy showed normalization of these findings in one CINCA/NOMID patient. Concerning audiological impairment, in 4 CINCA/NOMID patients (aged 3-24 years) the abnormal audiogram findings remained unchanged despite the 2 years treatment with canakinumab. Finally, the resolution of macular oedema was observed for 1 eye of a CINCA/NOMID patient and clinical improvement in blepheratis was recorded in another CINCA/NOMID subject. Notably, during this study almost 50\% of CINCA/NOMID patients required an adjustment of the dose and/or frequency of drug administration [52]. In a subsequent open study conducted in Italy in patients previously enrolled in the aforementioned trial, the median dose of canakinumab in CINCA/NOMID patients after 12 months was $4 \mathrm{mg} / \mathrm{kg}$ with a mean frequency of administration of 5 weeks [53], suggesting that the initial dose of canakinumab in CINCA/NOMID patients should be higher than $2 \mathrm{mg} / \mathrm{kg}$ every 8 weeks, which, instead, represents the staring dose in the milder forms of CAPS spectrum such as FCAS and MWS. Due to the extreme rarity of the disease, few data are available on treatment of most severe CINCA/NOMID patients during the first year of life. Unfortunately, this period is absolutely critical because most of the cerebral damage secondary to the persistent inflammation occurs right in the early phases of the mental development. Thus, a crucial point in CINCA/NOMID patients with severe phenotype is the therapeutic management during the first year of life. While, in fact, it has been demonstrated in non-human primates that the diffusion of anakinra in the CNS is proportional to the systemic dose, there is no clear evidence regarding whether, and in which proportion, the new anti-IL-1 drugs may be actually capable of passing through the blood-brain barrier therefore allowing to control the disease activity in the CNS in these patients with more severe CINCA/NOMID phenotype. Six patients were enrolled and treated with canakinumab after anakinra withdrawal in a recent open-label study [55]. In this study, all 6 patients required a dose escalation (i.e. from $150 \mathrm{mg}$ or $2 \mathrm{mg} / \mathrm{kg}$ in patients $<40 \mathrm{Kg}$ to $600 \mathrm{mg}$ or $8 \mathrm{mg} / \mathrm{kg}$ in patients $<40 \mathrm{Kg}$ every 4 weeks).
Treatment with canakinumab improved symptoms and serum inflammatory signs, although low-grade CNS leukocytosis persisted in 4 patients and headaches was still affecting 1 patient despite ongoing treatment. In patients with CINCA/NOMID that progressed into intellectual disability, speech and psychomotor therapy were often required. Hearing loss often led to the need of supporting hearing devices or cochlear implants. Thus, the daily clinical management of patients with CINCA/ NOMID is extremely complex and only recently, evidence-based recommendations have been developed with particular attention to the management of all form of CAPS spectrum and other autoinflammatory diseases. According to these recommendations, use of anti-IL-1 is indicated for whole spectrum of CAPS, at any age (level of evidence 1B-2A) and long-term IL-1 inhibition should be started as early as possible in patient with active disease to prevent organ damage [56]. There is general consensus on the opportunity to ask for a specific anti-IL-1 treatment also in those patients with a clinical picture highly consistent with a CAPS phenotype that turned out to be negative for germ-line mutations [45].

\section{Prognosis}

Intellectual disability is often enlightened as the main relevant prognostic factor and it develops in the first years of life. Its severity is proportional to the delay of the diagnosis and of the beginning of appropriate antiIL-1 treatment. Prognosis of CINCA/NOMID syndrome has been dramatically improved by the availability of anti-IL-1 drugs. In the past, the life prognosis was significantly affected by several complications, including the development in the adult age of renal amyloidosis, responsible for the occurrence of chronic renal failure. Even if no direct evidences are available so far, it is conceivable that the dramatic control of the systemic inflammation using anti-IL-1 will sensibly reduce the risk of the occurrence of this complication. Lane et al. in 2013 described 4 CAPS patients with amyloidosis treated with anti-IL-1 agents. Of the 4 patients, 1 had received a renal transplant prior to initiation of this treatment; all the remaining 3 patients have a resolution of proteinuria over the follow-up period. However, 3 of the 4 patients had a stable chronic kidney disease and in 1 patient disease progressed from stage 1 to stage 2 over the 11years follow-up period. These findings suggest that even in patients with established amyloidosis, effective treatment of the underlying syndrome can lead to improved renal function and regression of amyloid, as long as renal impairment is not too advanced at time of diagnosis [57]. It may be reasonable that patients that have been treated since the first months of life will present a consistent reduction of long-term complication. However the progression of hearing loss has been described 
even in children that received a prompt diagnosis and treatment. In this line, more efforts are needed to provide evidence on the best possible treatment, dosage and frequency of administration of anti-IL-1 treatment in order to completely prevent the occurrence of these complications.

\section{Unresolved questions}

CINCA/NOMID syndrome is a relatively new disease and the research exploring the underlying pathogenetic mechanisms is constantly growing. Moreover, while the clinical outcome is known for those patients who did not receive treatment with anti-IL-1, the outcome through adulthood of the patients who received anti-IL1 treatment in the infancy is still unknown. Regarding the new anti-IL-1 drugs, the percentage of these drugs reaching the CNS and therefore the possibility to prevent the development of intellectual disability and brain atrophy, above all in young children, it is unclear.

\section{Conclusion}

CINCA/NOMID syndrome is a rare autoinflammatory syndrome. Recently, the pivotal role of IL-1 in the disease pathogenesis allowed to develop standard therapy with anti-IL-1 agents that have dramatically changed the prognosis during last years.

\begin{abstract}
Abbreviation
ASC: Apoptosis-associated speck-like protein containing C-terminal caspase recruitment domain; CANDLE: Chronic Atypical Neutrophilic Dermatosis with Lipodystrophy and Elevated temperature; CAPS: Cryopyrin-associated periodic syndromes; CARD: Caspase activation and recruitment domains: CINCA: Chronic infantile neurological cutaneous and articular syndrome; CNS: Central nervous system; DAMPs: Damage-Associated Molecular Patterns; FCAS: Familial cold autoinflammatory syndrome; IL-1: Interleukin1: LPS: Lipopolysaccharide; MHC: Major Histocompatibility Complex; MRI: Magnetic Resonance Imaging; MWS: Muckle-Wells syndrome; NLRs: Leucine-rich repeat containing Receptor; NOD: Nucleotide-binding Oligomerization Domain; NOMID: Neonatal-onset multisystem inflammatory disease; PAMPs: Pathogen-Associated Molecular Patterns; PRRs: Patternrecognition receptors; PYD: Pyrin domain; ROS: Reactive oxygen species; SNHL: Sensorineural hearing loss; TLR: Toll like receptor
\end{abstract}

\section{Acknowledgements}

Not applicable.

\section{Funding}

No funding or sponsorship was received for this study or publication of this article.

\section{Availability of data and materials}

This article is based on a review of previously conducted studies and does not involve any new studies.

\section{Authors' contributions}

All the Authors made substantial contributions to conception of the article, participated in drafting the main text and viewed the final version. MF and $\mathrm{AO}$ also created figures and tables and critically revised the manuscript. AO and MG critically revised the manuscript, tables and figures for important intellectual content, and gave final approval of the version to be submitted.

\section{Competing interests}

Marco Gattorno: speaker's fees, consultancies and research grants from Novartis and SOBI.

Martina Finetti, Alessia Omenetti, Silvia Federici and Roberta Caorsi declare that they have no competing interest.

\section{Consent for publication}

All the authors gave the consent of publication. All authors of the manuscript have read and agreed to its content and are accountable for all aspects of the accuracy and integrity of the manuscript.

We have also obtained consent to publish images from the parents of the patients. Consent for publication of images was obtained and stored by our team.

\section{Ethics approval and consent to participate}

This article is based on a review of previously conducted studies and does not involve any new studies of human or animal subjects performed by any of the authors.

\section{Author details}

${ }^{1} \cup O$ Pediaria II, G. Gaslini Institute, Genoa, Italy. ${ }^{2}$ DINOMGI, University of Genoa, Genoa, Italy.

Received: 10 March 2016 Accepted: 16 November 2016

Published online: 07 December 2016

\section{References}

1. Hoffman HM. Rilonacept for the treatment of cryopyrin-associated periodic syndromes (CAPS). Expert Opin Biol Ther. 2009;9(4):519-31.

2. Cuisset L, Jeru I, Dumont B, Fabre A, Cochet E, Le BJ, et al. Mutations in the autoinflammatory cryopyrin-associated periodic syndrome gene: epidemiological study and lessons from eight years of genetic analysis in France. Ann Rheum Dis. 2011;70(3):495-9.

3. Lainka E, Neudorf U, Lohse P, Timmann C, Bielak M, Stojanov S, et al. Analysis of cryopyrin-associated periodic syndromes (CAPS) in German children: epidemiological, clinical and genetic characteristics. Klin Padiatr. 2010;222(6):356-61.

4. Levy R, Gerard L, Kuemmerle-Deschner J, Lachmann HJ, Kone-Paut I, Cantarini L, et al. Phenotypic and genotypic characteristics of cryopyrinassociated periodic syndrome: a series of 136 patients from the Eurofever Registry. Ann Rheum Dis. 2015;74(11):2043-9.

5. Sibley CH, Plass N, Snow J, Wiggs E, Brewer C, King K, et al. Sustained response and prevention of damage progression in patients with neonatalonset multisystem inflammatory disease (NOMID) treated with anakinra. Arthritis Rheum. 2012;31

6. de Almeida JA, Goldbach-Mansky R. Monogenic autoinflammatory diseases: concept and clinical manifestations. Clin Immunol. 2013;147(3):155-74.

7. Goldbach-Mansky R, Dailey NJ, Canna SW, Gelabert A, Jones J, Rubin BI, et al. Neonatal-onset multisystem inflammatory disease responsive to interleukin-1 beta inhibition. N Engl J Med. 2006;355(6):581-92.

8. Dollfus $H$, Hafner R, Hofmann HM, Russo RA, Denda L, Gonzales LD, et al. Chronic infantile neurological cutaneous and articular/neonatal onset multisystem inflammatory disease syndrome: ocular manifestations in a recently recognized chronic inflammatory disease of childhood. Arch Ophthalmol. 2000;118(10):1386-92.

9. Ahmadi N, Brewer CC, Zalewski C, King KA, Butman JA, Plass N, et al. Cryopyrin-associated periodic syndromes: otolaryngologic and audiologic manifestations. Otolaryngol Head Neck Surg. 2011;145(2):295-302.

10. Hill SC, Namde M, Dwyer A, Poznanski A, Canna S, Goldbach-Mansky R. Arthropathy of neonatal onset multisystem inflammatory disease (NOMID/ CINCA). Pediatr Radiol. 2007;37(2):145-52.

11. Prieur AM. A recently recognised chronic inflammatory disease of early onset characterised by the triad of rash, central nervous system involvement and arthropathy. Clin Exp Rheumatol. 2001;19(1):103-6.

12. Lepore L, Paloni G, Caorsi R, Alessio M, Rigante D, Ruperto N, et al. Followup and quality of life of patients with cryopyrin-associated periodic syndromes treated with Anakinra. J Pediatr. 2010;157(2):310-5.

13. Aksentijevich I, Nowak M, Mallah M, Chae JJ, Watford WT, Hofmann SR, et al. De novo CIAS1 mutations, cytokine activation, and evidence for genetic heterogeneity in patients with neonatal-onset multisystem inflammatory 
disease (NOMID): a new member of the expanding family of pyrinassociated autoinflammatory diseases. Arthritis Rheum. 2002;46(12):3340-8.

14. Feldmann J, Prieur AM, Quartier P, Berquin P, Certain S, Cortis E, et al. Chronic infantile neurological cutaneous and articular syndrome is caused by mutations in CIAS1, a gene highly expressed in polymorphonuclear cells and chondrocytes. Am J Hum Genet. 2002;71(1):198-203.

15. Arostegui II, Aldea A, Modesto C, Rua MJ, Arguelles F, Gonzalez-Ensenat MA, et al. Clinical and genetic heterogeneity among Spanish patients with recurrent autoinflammatory syndromes associated with the CIAS1/PYPAF1/ NALP3 gene. Arthritis Rheum. 2004;50(12):4045-50.

16. Neven B, Callebaut I, Prieur AM, Feldmann J, Bodemer C, Lepore L, et al. Molecular basis of the spectral expression of CIAS1 mutations associated with phagocytic cell-mediated autoinflammatory disorders CINCA/NOMID, MWS, and FCU. Blood. 2004;103(7):2809-15.

17. Tanaka N, Izawa K, Saito MK, Sakuma M, Oshima K, Ohara O, et al. High incidence of NLRP3 somatic mosaicism in patients with chronic infantile neurologic, cutaneous, articular syndrome: results of an International Multicenter Collaborative Study. Arthritis Rheum. 2011;63(11):3625-32.

18. Saito M, Fujisawa A, Nishikomori R, Kambe N, Nakata-Hizume M, Yoshimoto M, et al. Somatic mosaicism of CIAS1 in a patient with chronic infantile neurologic, cutaneous, articular syndrome. Arthritis Rheum. 2005;52(11):3579-85.

19. Saito M, Nishikomori R, Kambe N, Fujisawa A, Tanizaki H, Takeichi K, et al. Disease-associated CIAS1 mutations induce monocyte death, revealing lowlevel mosaicism in mutation-negative cryopyrin-associated periodic syndrome patients. Blood. 2008;111(4):2132-41.

20. Arostegui Jl, Lopez Saldana MD, Pascal M, Clemente D, Aymerich M, Balaguer $F$, et al. A somatic NLRP3 mutation as a cause of a sporadic case of chronic infantile neurologic, cutaneous, articular syndrome/neonatal-onset multisystem inflammatory disease: Novel evidence of the role of low-level mosaicism as the pathophysiologic mechanism underlying mendelian inherited diseases. Arthritis Rheum. 2010;62(4):1158-66.

21. Izawa K, Hijikata A, Tanaka N, Kawai T, Saito MK, Goldbach-Mansky R, et al. Detection of base substitution-type somatic mosaicism of the NLRP3 gene with $>99.9 \%$ statistical confidence by massively parallel sequencing. DNA Res. 2012;19(2):143-52.

22. Omoyinmi E, Melo GS, Standing A, Rowczenio DM, Eleftheriou D, Klein N, et al. Brief Report: whole-exome sequencing revealing somatic NLRP3 mosaicism in a patient with chronic infantile neurologic, cutaneous, articular syndrome. Arthritis Rheumatol. 2014;66(1):197-202.

23. Jimenez-Trevino S, Gonzalez-Roca E, Ruiz-Ortiz E, Yague J, Ramos E, Arostegui Jl. First report of vertical transmission of a somatic NLRP3 mutation in cryopyrin-associated periodic syndromes. Ann Rheum Dis. 2013; 72(6):1109-10.

24. Nakagawa K, Gonzalez-Roca E, Souto A, Kawai T, Umebayashi H, Campistol JM, et al. Somatic NLRP3 mosaicism in Muckle-Wells syndrome. A genetic mechanism shared by different phenotypes of cryopyrin-associated periodic syndromes. Ann Rheum Dis. 2015;74(3):603-10.

25. McDermott MF, Aksentijevich I, Galon J, McDermott EM, Ogunkolade BW, Centola $\mathrm{M}$, et al. Germline mutations in the extracellular domains of the $55 \mathrm{kDa}$ TNF receptor, TNFR1, define a family of dominantly inherited autoinflammatory syndromes. Cell. 1999;97(1):133-44.

26. Shaw PJ, Lamkanfi M, Kanneganti TD. NOD-like receptor (NLR) signaling beyond the inflammasome. Eur J Immunol. 2010:40(3):624-7.

27. Martinon F, Petrilli V, Mayor A, Tardivel A, Tschopp J. Gout-associated uric acid crystals activate the NALP3 inflammasome. Nature. 2006; 440(7081):237-41.

28. Masters SL, Simon A, Aksentijevich I, Kastner DL. Horror autoinflammaticus: the molecular pathophysiology of autoinflammatory disease $(*)$. Annu Rev Immunol. 2009;27:621-68.

29. Auron PE, Webb AC, Rosenwasser $L$, Mucci SF, Rich A, Wolff SM, et al. Nucleotide sequence of human monocyte interleukin 1 precursor CDNA. Proc Natl Acad Sci U S A. 1984;81(24):7907-11.

30. Ferrari D, Chiozzi P, Falzoni S, Dal SM, Melchiorri L, Baricordi OR, et al. Extracellular ATP triggers IL-1 beta release by activating the purinergic P2Z receptor of human macrophages. J Immunol. 1997;159(3):1451-8.

31. Andrei C, Dazzi C, Lotti L, Torrisi MR, Chimini G, Rubartelli A. The secretory route of the leaderless protein interleukin 1 beta involves exocytosis of endolysosome-related vesicles. Mol Biol Cell. 1999;10(5):1463-75.

32. Martinon F, Burns K, Tschopp J. The inflammasome: a molecular platform triggering activation of inflammatory caspases and processing of proll-beta. Mol Cell. 2002;10(2):417-26.
33. Dinarello CA. Immunological and inflammatory functions of the interleukin1 family. Annu Rev Immunol. 2009;27:519-50.

34. Rubartelli A, Gattorno M, Netea MG, Dinarello CA. Interplay between redox status and inflammasome activation. Trends Immunol. 2011;32(12):559-66.

35. Agostini L, Martinon F, Burns K, McDermott MF, Hawkins PN, Tschopp J. NALP3 forms an IL-1 beta-processing inflammasome with increased activity in Muckle-Wells autoinflammatory disorder. Immunity. 2004;20(3):319-25.

36. Gattorno M, Tassi S, Carta S, Delfino L, Ferlito F, Pelagatti MA, et al. Pattern of interleukin-1 beta secretion in response to lipopolysaccharide and ATP before and after interleukin-1 blockade in patients with CIAS1 mutations. Arthritis Rheum. 2007:56(9):3138-48.

37. Balow J, Sun H, Godbach-Mansky R, Kastner D, Aksentijevich I. Microarraybased gene expression studies of systemic inflammation in patients with cryopyrin-associated periodic syndromes (CAPS). Clin Exp Rheumatol. 2008; 26(2):178.

38. Tschopp J, Schroder K. NLRP3 inflammasome activation: The convergence of multiple signalling pathways on ROS production? Nat Rev Immunol. 2010;10(3):210-5.

39. Carta S, Tassi S, Delfino L, Omenetti A, Raffa S, Torrisi MR, et al. Deficient production of IL-1 receptor antagonist and IL-6 coupled to oxidative stress in cryopyrin-associated periodic syndrome monocytes. Ann Rheum Dis. 2012;71(9):1577-81.

40. Tassi S, Carta S, Delfino L, Caorsi R, Martini A, Gattorno M, et al. Altered redox state of monocytes from cryopyrin-associated periodic syndromes causes accelerated IL-1beta secretion. Proc Natl Acad Sci U S A. 2010; 107(21):9789-94.

41. Baroja-Mazo A, Martin-Sanchez F, Gomez Al, Martinez CM, Amores-Iniesta J, Compan V, et al. The NLRP3 inflammasome is released as a particulate danger signal that amplifies the inflammatory response. Nat Immunol. 2014; 15(8):738-48.

42. Federici S, Gattorno M. A practical approach to the diagnosis of autoinflammatory diseases in childhood. Best Pract Res Clin Rheumatol. 2014;28(2):263-76.

43. Federici S, Sormani MP, Ozen S, Lachmann HJ, Amaryan G, Woo P, et al. Evidence-based provisional clinical classification criteria for autoinflammatory periodic fevers. Ann Rheum Dis. 2015;74(5):799-805.

44. Sarrabay G, Grandemange S, Touitou I. Diagnosis of cryopyrin-associated periodic syndrome: challenges, recommendations and emerging concepts. Expert Rev Clin Immunol. 2015;11(7):827-35.

45. Hawkins PN, Lachmann HJ, McDermott MF. Interleukin-1-receptor antagonist in the Muckle-Wells syndrome. N Engl J Med. 2003;348(25):2583-4.

46. Lachmann HJ, Papa R, Gerhold K, Obici L, Touitou I, Cantarini L, et al. The phenotype of TNF receptor-associated autoinflammatory syndrome (TRAPS) at presentation: a series of 158 cases from the Eurofever/EUROTRAPS international registry. Ann Rheum Dis. 2013;21.

47. Hoffman HM, Rosengren S, Boyle DL, Cho JY, Nayar J, Mueller JL, et al. Prevention of cold-associated acute inflammation in familial cold autoinflammatory syndrome by interleukin-1 receptor antagonist. Lancet. 2004;364(9447):1779-85.

48. Lovell DJ, Bowyer SL, Solinger AM. Interleukin-1 blockade by anakinra improves clinical symptoms in patients with neonatal-onset multisystem inflammatory disease. Arthritis Rheum. 2005;52(4):1283-6.

49. Neven B, Marvillet I, Terrada C, Ferster A, Boddaert N, Couloignier V, et al. Long-term efficacy of the interleukin-1 receptor antagonist anakinra in ten patients with neonatal-onset multisystem inflammatory disease/ chronic infantile neurologic, cutaneous, articular syndrome. Arthritis Rheum. 2010;62(1):258-67.

50. Hoffman HM, Throne ML, Amar NJ, Sebai M, Kivitz AJ, Kavanaugh A, et al. Efficacy and safety of rilonacept (interleukin-1 Trap) in patients with cryopyrin-associated periodic syndromes: results from two sequential placebo-controlled studies. Arthritis Rheum. 2008;58(8):2443-52.

51. Lachmann HJ, Kone-Paut I, Kuemmerle-Deschner JB, Leslie KS, Hachulla E, Quartier $\mathrm{P}$, et al. Use of canakinumab in the cryopyrin-associated periodic syndrome. N Engl J Med. 2009;360(23):2416-25.

52. Kuemmerle-Deschner JB, Hachulla E, Cartwright R, Hawkins PN, Tran TA, Bader-Meunier B, et al. Two-year results from an open-label, multicentre, phase III study evaluating the safety and efficacy of canakinumab in patients with cryopyrin-associated periodic syndrome across different severity phenotypes. Ann Rheum Dis. 2011;70(12):2095-102.

53. Caorsi R, Lepore L, Zulian F, Alessio M, Stabile A, Insalaco A, et al. The schedule of administration of canakinumab in cryopyrin associated periodic 
syndrome is driven by the phenotype severity rather than the age. Arthritis Res Ther. 2013;15(1):R33.

54. Ter HN, Lachmann H, Ozen S, Woo P, Uziel Y, Modesto C, et al. Treatment of autoinflammatory diseases: results from the Eurofever Registry and a literature review. Ann Rheum Dis. 2013;72(5):678-85.

55. Sibley CH, Chioato A, Felix S, Colin L, Chakraborty A, Plass N, et al. A 24month open-label study of canakinumab in neonatal-onset multisystem inflammatory disease. Ann Rheum Dis. 2015;74(9):1714-9.

56. Ter Haar NM, Oswald M, Jeyaratnam J, Anton J, Barron KS, Brogan PA, et al. Recommendations for the management of autoinflammatory diseases. Ann Rheum Dis. 2015;74(9):1636-44.

57. Lane T, Loeffler JM, Rowczenio DM, Gilbertson JA, Bybee A, Russell TL, et al. AA amyloidosis complicating the hereditary periodic fever syndromes. Arthritis Rheum. 2013;65(4):1116-21.

58. Hoffman HM, Throne ML, Amar NJ, Cartwright RC, Kivitz AJ, Soo Y, Weinstein SP. Long-term efficacy and safety profile of rilonacept in the treatment of cryopryin-associated periodic syndromes: results of a 72-week open-label extension study. Clin Ther. 2012;34(10):2091-103.

Submit your next manuscript to BioMed Central and we will help you at every step:

- We accept pre-submission inquiries

- Our selector tool helps you to find the most relevant journal

- We provide round the clock customer support

- Convenient online submission

- Thorough peer review

- Inclusion in PubMed and all major indexing services

- Maximum visibility for your research

Submit your manuscript at www.biomedcentral.com/submit
Biomed Central 